Vol.3, No. 3, September, 2021, pp. 330-339, doi.org:10.52567/pjsr.v3i3.255

www.pjsr.com.pk

\title{
A SOCIOLOGICAL EXPLORATION OF CLIMATE CHANGE AND ITS' IMPLICATION FOR AGRICULTURAL ADAPTIVE STRATEGIES IN PUNJAB
}

\author{
Zia Mahmood \\ Ph.D. Scholar, Department of Rural Sociology, \\ University of Agriculture, Faisalabad \\ z.m.kashmire@gmail.com \\ Ashfaq Ahmad Maan \\ Professor (Rtd.), Department of Rural Sociology, \\ University of Agriculture, Faisalabad \\ Ashfaqmann@gmail.com \\ Izhar Ahmad Khan \\ Associate Professor, Department of Rural Sociology, \\ University of Agriculture, Faisalabad \\ Izharkhan99@uaf.edu.pk
}

\begin{abstract}
Agriculture plays vital role in economic growth, food security, employment generation and poverty alleviation. It contributes 19.2 percent to the GDP and provides employment to $38.5 \%$ of labor force. More than $65 \%$ to $70 \%$ of the population depends on agriculture for its' livelihood. The purpose of this study is to analyze the current situation of climate change and its implications' for agricultural adaptive strategies in Punjab. Three districts were selected randomly from the Central, North and south zone of the province by using multistage sampling technique. Qualitative information was collected through the key informant interviews from three selected districts namely Bahawalnagar, Chakwal and Faisalabad. An interview guide was used to collect the in-depth information from progressive farmers, agricultural officers, environmental officers and Ph.D. scholars. The farmers and experts were on the same page as the effects of climate change had been observed in the study area. On the basis of findings, it was concluded that climate change was accelerated by human interventions, and negative implications were observed in the form of decline in production and increase in the input cost of agricultural operation. Different agricultural adaptive strategies were used to cope with the issue of climate change. There were various behavioral and structural constraints in the process of adaptation to climate change.

Key words: Climate Change, Adaptive strategies, Implications, Vulnerable, Food security, Production

\section{INTRODUCTION}

Climate change has emerged on the global scale, and agriculture sector is most vulnerable to alteration in the climatic conditions. The increase in the average global temperature and erratic climatic conditions are posing a serious threat to agriculture, biodiversity and food security. Alteration in the global atmospheric structure, such as the increasing accumulation of carbon dioxide $\mathrm{CO} 2$ and other gases are visible effects of climate change which are bringing hidden hunger crisis in the communities by decreasing the essential nutrients in food crops (Joshia \& Chaturvedi, 2013; Arunanondchai et al., 2018).

Climate change has multiple impacts like rising sea level, shifting patterns of rainfall, significant changes in the average temperature, duration of seasons, increasing incidents of droughts especially in the semiarid areas, floods and strong winds with adverse effects on the crop production and rural livelihoods. High emission of gases like carbon dioxide (CO2), the intensity of Greenhouse Gases (GHGs), methane (CH4) and nitrous oxide (N2O) are accelerating the temperature and causing global warming. Among the numerous problems of the modern world, environmental change is one of the leading problems nowadays.
\end{abstract}


Global temperature is expected to increase between $1.8^{\circ} \mathrm{C}$ to $4^{\circ} \mathrm{C}$, beyond the average of $2.8^{\circ} \mathrm{C}$ in the past (Intergovernmental Panel on Climate Change [IPCC], 2007).

As the greater variability in the environment, like unprecedented alteration in temperature, rainfall and various changes in the global ecosystem, there are different responses by the crops and ecosystem. Climate change affects the integral agricultural processes and production in various dimensions. These effects can be categorized as changes in the soil moisture, alteration in the nutrient cycle, plant diseases, pest outbreaks, etc. All these factors leave adverse implications on food security, food production, food preservation and consumption (Fuhrer, 2003; Jones \& Thornton, 2003).

There are numerous factors which drive and shape the agricultural economy. Fluctuations in the market, changes in agricultural policies at domestic and international level (such as subsidies, tariffs, incentives and credit facilities), efficiency of extension services, land tenure mechanism, farm management practices and biophysical environment (water availability, carrying capacity, quality of soil, diseases and pests' outbreaks, etc.) are primary factors that influence the agricultural sector (Schmitz et al., 2015).

Growth of crops has been affected by rising temperature and duration of various stages of the crop is shortened, which ultimately decrease the yield of crops. Water is the most important factor in agriculture, and due to global warming, the hydrological cycle is affected and there is a need to adopt proper response measures to meet the future requirements of irrigation. And similarly, governmental policies, agricultural reforms and efficient power sector are very important to build climate-resilient communities (Boyd et al., 2009).

Mixed cropping, diversification of the crop, drought-resistant crop varieties, change in the planting, harvesting schedule and using different crop varieties are some of the adaptive strategies (Jagtap, 1995). The emission of Greenhouse Gases (GHG) has increased continuously between 1970 and 2010 and the maximum concentration observed between the period between 2000 and 2010 (IPCC, 2014). The landmass and surface of the oceans is heat up by the increasing temperatures, as the surface temperature increases the evaporation and cause change in the precipitation patterns (Adger et al., 2003 and Challinor et al., 2007).

Here are some future climate projections:

- The temperature increase is projected to be higher in Pakistan than the global average.

- The temperature in the northern parts of the country is projected to increase higher than the southern parts.

- It is expected that the number of hot days and nights will significantly increase.

- There will be unsystematic precipitation trends in Pakistan.

- There is an expected decrease in major crops such as wheat and rice.

- Per capita availability of water will be decreased to an alarming level.

- Another trend has been observed that precipitation is increasing in the Upper Indus Basin as compared to lower Indus Basin areas (Ahmed \& Suphachalasai, 2014; Chaudhry et al., 2009; Iqbal \& Zahid, 2014).

\section{PROBLEM STATEMENT}

Presently, the agriculture sector is under stress due to environmental variations. Climate Change and its' implications are a potential threat to agriculture and ecological resources. Survival of human beings is based on the necessary adjustment with the sensitive mode of nature, and it depends on the principle of mutual respect. If nature is not preserved or looked after properly, then it has the potential to hit back and any other maladjustment of man may bring disaster in one or other form.

\section{SIGNIFICANCE OF THE STUDY}

There is a serious need of resilience-building to face the hazards of climate change because few studies have been carried out to analyze the necessary adoption strategies, or we can say the resilience-building to climate change in Pakistan. To fill this existing knowledge gap and give the realization of environmental change, this study is designed optimistically to analyze the current situation of climate change. 
This research focuses on the following questions:

- What do you know about the climate change and its' implications for agricultural adaptive strategies?

- What are the general causes of climate change and also share your knowledge regarding the anthropogenic dimensions of climate change?

- In your opinion, what are the present and future implications of climate change for PunjabPakistan?

- What are different effective agricultural adaptive strategies in response to climate change?

- What are the implications of these adaptive strategies for agriculture?

- What are some of the constraints in adapting climate change?

- What will you recommend for policy implications?

\section{REVIEW OF LITERATURE}

Kandlinkar and Risbey (2000) discussed that bringing socio-economic uplift in the status of farmers can improve the adaptation process and will contribute significantly to mitigate the negative implications of climate change in the short and long term. And for the better adaptation of climate, there should also be a vibrant market that address the needs of the farmers. It means that education, skills, financial positioning of the farmers and their connectivity with the market available technology is important factor in the development of adaptive capacity.

Pan et al., (2003) observed that the warmer climate has become a potential threat to the Asian wetlands areas. Many areas are facing droughts, and there are significant changes in the precipitation of delta regions of Bangladesh, China, India, and Pakistan. This warmer climate is drying up wetlands and degrading the composition of ecosystems in South Asia.

Nhemachena and Hassan (2007) stated that farmers would be able to change their management practices and adaptive strategies if they have financial wellbeing and necessary resources (mechanization) to cater the implications of climate change in Southern Africa. Moreover, a better network of information and skill development will increase the confidence and capacity of the farmers in adaptation. It shows that farmers need financial resources to utilize new technology along with relevant information and proper guidance.

Savage and Suleri (2007) reported that individuals who are living in a catastrophe inclined areas have their own adaptive system to deal with the climate change based on thier indigenous knowledge, social and physical capital. In developing countries, people use their social network and adaptive strategies to overcome the losses caused by climate change. Sometimes, they migrate to the areas within the country or abroad as an adaptive strategy and send remittances to lessen the vulnerability of their relatives living in these areas. Whereas, people living in the catastrophe inclined areas of the developed countries rely on the insurance to compensate losses caused by climate change. As climate change and agriculture will remain in spotlight in the future, the governemnt need to develop a social protection network in disaster-prone areas.

International Fund for Agricultural Development (IFAD, 2010) reported that effects posed by changing climate cannot be avoided only by adaptation or mitigation. It is necessary to raise awareness to build climate-resilient communities in rural areas. Awareness-raising is a viable option of combating climatic variations in the short and long term.

Pande and Akermann (2010) reported in their research that livelihood of the farmers is dependent on agricultural related activities. Moreover, agriculture and its' allied activities are closely related to the natural resources and highly vulnerable to the variations in climate, especially in arid and semi-arid areas due to absence of irrigation facilities. The rural communities have to develop a new dimension of income generation and reliable adaptive process to deal with the implications of climate change.

Pettengell (2010) discussed that effective weather forecast is an important factor in agriculture as it facilitates the farmers to plan their activities, what to do and when to do in the field. The seasonal patterns have been changed over the years and traditional farming calendars is no more effective. Farmers 
are in need of guidance for making plan for their crops because weather forecasts are the deciding factor when to sow the seeds and what is the proper time to harvest, and also seasonal forecasts that guide them what type of crop to sow and how to mitigate the climate effects by managing risks. Change in seasonal and erratic rainfall patterns have immense effects on farming cycles in all over the world. Problem is alarming in most of the developing countries which are experiencing more extreme events, changes in seasons and delayed onset of rainy seasons as rainfall being concentrated into fewer areas.

Abid et. al. (2014) examined the perception of farmers regarding climate change and their adaptive strategies in response to change in climate, a sample of 450 farm household was analyzed from three districts of three different agro-ecological zones of Punjab. The research conclude that that climate change awareness persists in the study area, and farmers made necessary adaptive strategies to adjust their agriculture in response to climatic change. About $58 \%$ of the households adapted practices in response to changing climate in the study area. The major adaptive farming practices were change in planting dates, change in crop varieties, and change of fertilizers and plantation of trees by the farmers.

\section{THEORETICAL FRAMEWORK}

The theoretical framework is very important in the social sciences research as it provides the fundamental base of reason regarding the occurrence of a specific phenomenon in a larger context of the different social perspectives.

\section{Induced Innovation theory}

Hayami and Ruttan (1971) described that the adaptive and sustainable agriculture is very important for the economic growth of the world. Induced innovation theory of Hicks has relevance to climate change. The exponential growth of population is stimulating factor in global initiatives and strategies to cope with climate change. The innovative step that comes as replacement of that factor ensures lesser cost and high profit. The farmers try to use alternatives of costly items to reduce the cost of production and to increase profitability

It is very important to explain how Hick's macroeconomic theory may relate to climate change and agriculture adaptation. Let's suppose a situation in which the demand for agricultural-related products increases as a consequence of either increased household income or population growth. Hick's theory states that in such condition, prices of the input products for which supply is inelastic will increase relative to prices of more elastic input products. Here, the government needs to be intervened. It is quite obvious that the farmers cannot develop these innovations themselves at the local level, and therefore it is the responsibility of the agricultural research institutions to develop innovative technologies and modernized machinery which supply firms can sell to local farmers to solve their farm-related problem and increase profit. Positively, these developments will lead to a significant reduction in farmer's unit costs in the best possible way as most of the agricultural adaptive strategies are expensive.

\section{Capacity building approach}

To maximize the utilization of the existing resources, technologies and knowledge, it is very important to enhance the institutional strength and capacity building at each level. In the context of climate change, supporting practical learning, building networks of collaboration and sharing and generating of knowledge are core values to develop the adaptive capacity of the people (De Lange \& Van Rooyen, 2002). The development of the agriculture sector in Pakistan is directly related to the ability of manpower involved and employed in farming. Capacity-building of people involved in agriculture is not a snapshot activity rather it is a continuous and complex process to update the skills of the farming community. The capacity building term is not limited to farmers but also includes research institutes, educational institutions (college \& Universities) and agriculture personnel, etc.

This is very effective approach as it improves knowledge of farmers; develops leadership skills in them, facilitates them on the principle of self-learning, supports use of indigenous knowledge of plant protection, identifies their problems, encourages the use of fertilizers, reduces cost of production, provides systematic training, management of farm activities, facilitates in assessment of various 
technologies, confidence building, situation analysis and rises the socio-economic status of rural communities (Khatam et al., 2010).

\section{The theory of planned behavior (TPB)}

The core principle of this theory is to analyze the intention of individuals to perform a certain type of behavior. Farmers are aware of climatic variations, but unable to perform adaptive behavior because of certain barriers, despite their intention to act accordingly. According to Ajzen (2005), intention is an immediate determinant of a certain behavior which means, stronger the intention of performing a certain behavior, the more likely to be performed by the individual. This theory also considers that if a person has the opportunities, resources, and intentions to perform the behavior, he must succeed in performing it. Similarly, this approach provides the guideline to analyze the perception of farmers, how this perception develops, where are the constraints found and what opportunities exist in farmers' adaptive behavior in response to climate change.

This theory can be used in study of the implications of climate change upon agriculture adaptive strategies as it predicts the behavioral intention and actual behavior of voluntary use of climate change adaptive strategies. It also provides an understanding of the dimensions of climate information perceived and reflected in the decisions of farmers.

\section{Rationale of Theories}

Building theories for the understanding of social phenomena is a tradition in social sciences. Although climate change is something quite natural and biophysical, adjustment and adaptation with it can be manipulated according to need of the hour. All of the above-mentioned theories focus on the use of technology and participation by farmers to cope with the implications of climatic variations at the grassroot level.

\section{MATERIALS AND METHODS}

Methodology is an organization of a set of clear actions and laws on which the entire research is established (Nachmias \& Nachmias, 1996). The qualitative analysis is based on the interviews of key informants. Key informants indepth interview is a research technique to gather specific qualitative information from "informants" who are usually experts about the research topic or community knowledge (Gilchrist, 1992). The researcher used an interview guide with the pre-determined open-ended questions to get the views of respondents on the issues of climate change and its' implications for agricultural adaptive strategies.

Qualitative analysis is used to obtain information about the opinion, values, beliefs, and behaviour of the unit of analysis. The qualitative data was analysed manually using content analysis technique. In conventional content analysis, coding categories are derived directly from the text data (Hsieh \& Shannon, 2005).

\section{Detail of Key informant interviews conducted the entire research period}

\begin{tabular}{|l|c|l|}
\hline Environmental officers & No. of informants & \multicolumn{1}{c|}{ Tehsil/Departments } \\
\hline Assistant Research Officer & 3 & Bahawalnagar: 1, Chakwal: 1, Faisalabad: 1 \\
\hline Progressive farmers & 3 & $\begin{array}{l}\text { Climate Change Research Centre, Faisalabad, Ayub } \\
\text { Agricultural Research Institute. }\end{array}$ \\
\hline DDO (Agri Extension) & 12 & from each selected tehsil \\
\hline Ph. D. Scholars & 3 & $\begin{array}{l}\text { Bahawalnagar: 1, Chakwal: 1, Faisalabad: 1 } \\
\text { from rural Sociology Department and 5 from } \\
\text { institute of Agricultural Extension and Rural } \\
\text { Development }\end{array}$ \\
\hline
\end{tabular}


This research was conducted in the Punjab, 3 districts (Bahawalnagar, Chakwal and Faisalabad) were selected randomly from the three different zones of the Punjab and at the $2^{\text {nd }}$ stage, two tehsils were selected from each of these districts. And at the last stage, progressive farmers, environmental officers and Agriculture Extension officers were interviewed by using snow ball sampling technique. Remaining respondents were selected by purposive sampling technique from climate change research Centre-Ayub Agricultural Research Institute, rural sociology and extension departments of university of Agriculture Faisalabad. The criterion of selection was: (1) Experts from research institute, having specialization in agriculture and climate change; and (2) Ph.D. Scholars of rural sociology and extension department, who are working in climate change projects and thesis research. The selection of the techniques, tools and targeted participants are very important in the reliability of the data. 30 key informant interviews were conducted by the researcher to get detailed information regarding the phenomenon. On average, each interview lasted 25 to 30 minutes.

\section{RESULTS AND DISCUSSION}

The main purpose was to find implications of climate change upon agriculture adaptive strategies in the province of Punjab. Keeping in the view of the research objectives, probing questions were asked from the experts. They gave their opinion and required information in Urdu and English as most of the participants were highly educated. The collective consensus of the respondents is presented in an integrative manner. The crux of their answers are:

\section{Knowledge of climate change and its implications}

Respondents told that climate change is something different from the weather change, as weather change is temporal, but climate change is an alteration in the weather pattern over a consistent time period, which may be observed within one or two decades. Most of them explained it as seasonal alteration, some as temperature change and some as a change in precipitation patterns, and they were also aware of its' effects upon agriculture as climate change and agriculture are highly interdependent on each other. They expressed their views that climate change has immensely affected the crops and other agricultural adaptive strategies in the province. The fluctuation in the prices of the crops and other agricultural products, availability of the items and other agriculture processes are highly dependent on the climate change.

\section{Role of human beings and causes of climate change}

Respondents were of the view that climate change is a natural phenomenon but mankind has mastered nature by the process of industrialization and mega structural transformation in the earth landscape. Climate change has an association with the increasing population and their activities. Human activities are the main cause of the growing risk of climate change.

Majority of the respondents told there were some natural causes of climate change i.e., solar radiation of the sun and variations in the movement of the earth in its orbit, etc. Earth temperature is increasing due to depletion of the ozone layer which absorbs ultraviolet radiations. They further explained that another contributing factor of changing climate is a high concentration of $\mathrm{CO} 2$ caused by human activities like deforestation, emission from the power plant, factories, and automobiles. Carbon dioxide absorbs infrared radiation which comprises the bulk of the energy from the sun. Respondents explained the interventions of the human beings in a holistic way as climate change was anthropogenic in nature which can only manage by effective planning. One of the informants said:

"Ye dunia Allah ne banai hai pr is ski ye halaat insann ne banai hai"

(Allah Almighty has created this world in a well-mannered way, but mankind has polluted it)

\section{Implications of climate change for agriculture}

As the majority of the respondents were experts, they explained that there are various variables of climate change like alteration in the rain, temperature, moisture in the air, floods, and number of gases in the atmosphere that constitutes the climate as a whole. And they further explained that all these factors had 
interaction with the crops, water, soil and wind etc. They explained that all these things have their specific effects on agriculture, which cannot be specified nor undermined. Due to technological development and advanced agriculture varieties and technique, many countries have increased their production and almost doubled their per acre yield. But the situation in Pakistan has not changed significantly as our farmers are still using the traditional way of farming and climate change is one of the major challenge that needs to be addressed.

A number of respondents agreed that the implications of changing climate were visible in the past and have the potential to affect agriculture in the future. A respondent referenced international research that:

"higher temperature and shifting patterns of rainfall have immense implications on agriculture as the production of wheat in South Asia will likely to reduce 50\% by the year of 2050, almost equal to $7 \%$ of global crop production."

Most of the respondents were strong advocates of climate preservation policies. Another respondent told that; "Pakistan has been ranked as $7^{\text {th }}$ most affected country of the world by climate change" so how we can expect that our agriculture will not be affected by climatic variations.

\section{Effectiveness of agricultural adaptive strategies}

Majority of the respondents held view that it is need of an hour to build climate-resilient rural communities, which is not possible without the efficient and practical adaptive strategies. Different respondents had different views regarding the effectiveness of adaptive strategies. However, they identified changes in the timing of farming operations, use of high yield verities, drought-resilient crop verities, mixed farming, diversifying household income, use of fertilizer and pesticide and intensify irrigation, etc. According to the majority of respondents, it is very difficult to identify any of the adaptive strategies as most effective because each strategy depends upon the environmental and biophysical condition of the respective area and its' acute application is also important at the farmer end. These strategies differ from area to area. So, the farmers are in need of proper awareness and guidance regarding adaptive strategies, keeping in view of their specific crop and biophysical environment of the area. Respondents told that criteria of effectiveness have many dimensions in terms of social acceptance, usage flexibility, compatibility with the institutional setting, the capacity of the farmers to implement, net outcomes and economic efficiency in the perception of the farmer.

\section{Implications of agricultural adaptive strategies}

A number of respondents highlights the effects of global warming; frequent extreme weather events like droughts, alteration in patterns of rainfall, alteration in seasonal patterns and shortening of the growing season have been observed in many areas of Pakistan. All these changes have serious implications for agriculture, and farmers are altering their farming practices. After analyzing the response of this question, it is concluded that implications for climate change are more serious in Upper Punjab and South Punjab. As the district Chakwal was an arid area where agriculture totally dependent upon the rainwater, and alternate arrangements are difficult to manage. The district Bahawalnagar was selected in South Punjab, where agriculture is affected due to shortage of water in the river Sutlej.

\section{Constraints in adaptation}

Most of the respondents said that as agriculture is a complex system, there are several barriers at farmer's level including structural, institutional and market level. Some of these constraints are; shortage of water, soil fertility and nutrients issues, ineffective extension services, reducing crop productivity due to shortage of water and changing patterns of rainfall, inability of the farmers to act accord with weather forecast, insufficient information regarding climate change, lack of resources and believe in traditional seasonal calendar. Most of the respondents also believed that there are some psychological barriers that need to be removed. It is very difficult to change the perception of the rural community without effective interventions. Capacity building issues of the farmers is another field which needs consideration to access if skill transferring to farmers is either perceived or not, if perceived, then implemented or not, etc. 
Many of the respondents highlighted that there are some structural constraints faced by the farmers like; availability of the fertilizers, pesticides, provision of high yield varieties, hybrid seeds, and subsidies on different input items by the governments, etc. Overall, it is concluded that the responsibility cannot be put only on the farmers, but the government is also equally responsible for these constraints.

\section{RECOMMENDATIONS}

The collective responses of the key informant interviews were summarized as climate change has serious implications for rural adaptive strategy. It is need of an hour to build climate-resilient rural communities to sustain the present and increase the future agriculture production as per national and international demand. The government should make an integrative policy which addresses the structural and farmer's level constraint. In most of the cases, the good understanding level was found in farmers regarding challenges of climate and they also knew appropriate adaptive strategies to cope with these problems. But they did not have the desired capacity to implement these adaptive strategies due to financial and technical constraints in the process of the effective adaptation process.

This also explained that there is a need for adaptive research to cope with climate change to increase agricultural production in Punjab. Because adaptation with climate change is not the only solution but to clean and preserve the environment is another challenging task for Pakistan. The role of government is very important in raising awareness regarding climate change. Governments make legislation, implement the laws, drive research initiatives, provide funds to the projects, monitor the current scenario of the problem and also predict the future projection. As Pakistan is ranked $7^{\text {th }}$ most affected country by the effects of climatic variations, it is the responsibility of the government to take necessary actions and fulfill its' national as well as international commitments.

Adaptation strategies should be decentralized on the principles of bottom-up approach; addressing the indigenous needs in analytical steps, keeping in view biophysical environment and eliminating the socio-economic barriers in response to climate change. However, respondents told that there should be innovative measures need to be taken as crop insurance, smart agriculture, social protection of farmers and subsidized technologies to decrease the vulnerability of the farmer.

\section{CONCLUSION}

On the basis of research findings, it is concluded that the climate change has been stressing the socioeconomic and ecological systems in Pakistan, which are already under significant stress due to the process of rapid urbanization, industrialization, emergence of corona and mass scale infrastructural development. Respondents were well aware and able to identify the causes and effects of climate change that has been observed over the past two decades. They pointed out that climate change and environmental degradation has been stimulated by human interventions. Different agricultural adaptive strategies were used by the farmers to cope with the implication of climate change i.e., use of high yield varieties (HYVs), drought resilient verities, use of fertilizers and pesticides, change in crop time and change in planting dates. The implications of climate change have been observed in the form of reduction in income and production and increased input prices (fertilizer, pesticide, hybrid seed, mechanization etc.). Multiple structural and behavioral constraints were identified including lack of credit, low level of technology, farm size, ineffective weather forecasting, less interest of the farmers and property related issues in the adaptation. There is need to integrate the indigenous knowledge of climate change with operational adaptive strategies through effective monitoring and evaluation system.

\section{REFERENCES}

Abid, M., Scheffran, J., Schneider, U.A. \& Ashfaq, M. (2014). Farmers' perceptions of and adaptation strategies to climate change and their determinants; the case of Punjab province, Pakistan. Earth System Dynamics, 5, 1359-1406. 
Adger, W. N., Hug, S., Brown, K., Conway, D., \& Hume, M. (2003). Adaptation to climate change in developing world. Progress in Development Studies, 3 (3), 179-195.

Ahmed, M. \& Suphachalasai, S. (2014). Assessing the Cost of Climate Change and Adaptation in South Asia. Manila: ADB.

Ajzen, I. (2005). Attitude, Personality and Behavior. Open University Press, Maidenhead.

Arunanondchai, P., Fei, C., Fisher, A., McCarl, B.A., Wang, W., \& Yang, Y. (2018.) The Routledge Handbook of Agricultural Economics. Routledge; Abingdon-on-Thames, UK: How doeas climate change affect agriculture.

Boyd, E., Hultman, N., Roberts, T. J., Corbera, E., Cole, J., Bozmoski, A., Ebeling, J., Tippmann, R., Mann, P., Brown, K., \& Liverman, D.M. (2009). Reforming CDM for Sustainable Development', Environmental Science and Policy.

Challinor, A., Wheeler, T., Garforth, C., Craufurd, P. \& Kassam, A. (2007). Assessing the vulnerability of food crop systems in Africa to climate change. Climate Change, 83, 381-399.

Chaudhry et al. (2009). Climate Change Indicators of Pakistan. Technical Report. No. 22. Islamabad: Pakistan Meteorological Department.

De Lange, A. \& Rooyen, J. Van. (2002). "The Current Status in Training for Agribusiness" in Readings in Agribusiness: A Source Book for Agribusiness Training, eds. C.J. Van Rooyen, O.T. Doyer, L. D'Haese \& F. Bostyn, University of Pretoria, Pretoria.

Fuhrer J. (2003). Agro ecosystem responses to combinations of elevated CO2, ozone, and global climate change. Agriculture, Ecosystems \& Environment, 97, 1-20.

Gilchrist, V. J. (1992). Key informant interviews. In B. F. Crabtree \& W. L. Miller (Eds.), Doing qualitative research. Sage Publications, Inc

Hayami, Y., \& Ruttan, V.M. (1971). Induced Innovation in Agricultural Development. Retrieved from: https://conservancy.umn.edu /bitstream/ handle /11299/54243/1971-03. pdf? sequence $=1$.

Hsieh, H.F., \& Shannon, S.E. (2005). Three approaches to qualitative content analysis. Qualitative Health Research, 15(9), 88-127

International Fund for Agricultural Development. (2010). Livestock and climate change, IFAD publishers.

Intergovernmental Panel on Climate Change. (2007). Climate Change 2007: Impacts, adaptation and vulnerability. Contribution of Working Group II to the Fourth Assessment Report of the Intergovernmental Panel on Climate Change, Cambridge, UK: Cambridge University Press.

Intergovernmental Panel on Climate Change. (2014). Climate Change 2014: Synthesis Report. Contribution of Working Groups I, II and III to the Fifth Assessment Report of the Intergovernmental Panel on Climate Change [Core Writing Team, R.K. Pachauri and L.A. Meyer (eds.)]. IPCC, Geneva, Switzerland.

Iqbal, W., \& Zahid, M. (2014). Historical and Future Trends of Summer Mean Air Temperature over South Asia. Pakistan Journal of Meteorology, 10(20)

Jagtap, S. S. (1995). Discovery and innovation changes in annual, seasonal and monthly rainfall in Nigeria and consequences to agriculture. Journal of African Academic science, 7(4), 311-426.

Joshia, K., \& Chaturvedi, M. (2013). Impact of Climate Change on Agriculture. Octa Journal of Environmental Research, 1(1), 39-42.

Kandlinkar, M., \& Risbey, M. (2000). Agricultural impacts of climate change: If adaptation is the answer, what is the question? Climate Change, 45, 529-539.

Khatam, A. (2010). Analysis of Farmers' Field Schools as an Alternative Extension Strategy to Benefit Resource Poor Farmers from Existing Agricultural Technologies in the Central Region of NWFP, Pakistan. [Doctoral dissertation, University of Agriculture, Faisalabad].

LeCompte, M. D., \& Preissle, J. (1993). Ethnography and qualitative design in educational research. Academic Press.

Nachmias, C. F. \& Nachmias, D. (1996). “Research Methods in Social Sciences. Arnold. 
Nhemachena, C., \& Hassan, R. (2007). Micro-level analysis of farmers' adaptation to climate change in Southern Africa, IFPRI Discussion Paper No. 00714, International Food Policy Research Institute, Washington DC, USA.

Pan, X.L., Deng, W., \& Zhang, D.Y. (2003). Classification of hydrological landscapes of typical wetlands in Northeast China and their vulnerability to climate change. Research of Environmental Sciences, 16, 14-18.

Pande, P., \& Akermann, K. (2010, March). Adaptation of small scale farmers to climatic risks in IndiaSustainet. Retrieved from: https://www.yumpu.com/en/document/view/11741852/adaptation-ofsmall-scale-farmer s-to-climatic-risks-in-india-sustainet.

Pettengell, C. (2010, April). Climate change adaptation, enabling people living in poverty to adapt. Retrieved from: https://policy-practice.oxfam.org/resources/climate-change-adaptation-enablingpeople-living-in-poverty-to-adapt-111978/

Savage, K., \& Suleri, A.Q. (2007). Remittances in crises: A case study from Pakistan. HPG Working Paper.

Schmitz, O.J., Lawler, J.J., Beier, P., Groves, C., Knight, G., Boyce, D.A., Bulluck, J., Johnston, K.M., Klein, M.L., Muller, K., Pierce, D.J., Singleton, W.R., Strittholt, J.R., Theobald, D.M., Trombulak, S.C., Trainor, A. (2015). Conserving biodiversity: Practical guidance about climate change adaptation approaches in support of land-use planning. Natural Areas Journal, 1, 190203. 